Article

\title{
Experimental Research of High-Pressure Methane Pulse Jet and Premixed Ignition Combustion Performance of a Direct Injection Injector
}

\author{
Shenggang Guo ${ }^{1}$, Yan Lei ${ }^{2, *}$, Xiaofeng Wang ${ }^{2}$, Tao Qiu ${ }^{2}$, Bin Pang ${ }^{1}$, Lei Shi ${ }^{1}$ and Xuehui An ${ }^{1}$ \\ 1 State Key Laboratory of Engine Reliability, Weichai Power Co., Ltd., Weifang 261061, China; \\ guosg@weichai.com (S.G.); pangb@weichai.com (B.P.); shilei02@weichai.com (L.S.); anxh@weichai.com (X.A.) \\ 2 Department of Automotive Engineering, Beijing University of Technology, Beijing 100124, China; \\ Wangxf7280@emails.bjut.edu.cn (X.W.); qiutao@bjut.edu.cn (T.Q.) \\ * Correspondence: leiyan@bjut.edu.cn; Tel.: +86-10-6739-1655; Fax: +86-10-6739-1985
}

\section{check for} updates

Citation: Guo, S.; Lei, Y.; Wang, X.; Qiu, T.; Pang, B.; Shi, L.; An, X. Experimental Research of HighPressure Methane Pulse Jet and Premixed Ignition Combustion Performance of a Direct Injection Injector. Processes 2021, 9, 1977. https://doi.org/10.3390/pr9111977

Academic Editors: Jianbing Gao, Guohong Tian, Thanos Megaritis and Rui Chen

Received: 30 August 2021

Accepted: 2 November 2021

Published: 5 November 2021

Publisher's Note: MDPI stays neutral with regard to jurisdictional claims in published maps and institutional affiliations.

Copyright: (c) 2021 by the authors. Licensee MDPI, Basel, Switzerland. This article is an open access article distributed under the terms and conditions of the Creative Commons Attribution (CC BY) license (https:// creativecommons.org/licenses/by/ $4.0 /)$.

\begin{abstract}
Natural gas (NG) direct injection (DI) technology benefits the engine with high efficiency and clean emissions, and the high-pressure gas fuel injection process causes crucial effects on the combustion. This study presents an optical experimental investigation on the high-pressure methane single-hole direct injection and premixed ignition combustion based on a visualization cuboid constant volume bomb (CVB) test rig. The experimental results show that the methane jet process is divided into two stages. The methane gas jet travels at a faster speed during the unstable stage I than that during the stable stage II. The injection pressure causes more influence on both the jet penetration distance and the jet cone area during stage II. The methane jet premixed flame is a stable flame with a nearly spherical shape, and its equivalent radius linearly increases. The methane jet premixed flame area also increases while the flame stretch rate declines. The methane jet premixed flame velocity rises as both the standing time and equivalent ratio increase. The methane jet premixed flame is a partial premixed flame, and the peak of the methane jet premixed flame occurs at greater equivalence ratio $\phi$, i.e., $\phi>2$. As the injection pressure rises, the jet premixed flame equivalent radius increases, and the flame velocity linearly increases. The higher the methane injection pressure, the faster the jet premixed flame velocity.
\end{abstract}

Keywords: direct injection; methane; gas jet; premixed ignition; constant volume bomb (CVB)

\section{Introduction}

Natural gas (NG) is a low-carbon fuel, and is widely used in the practical industry such as power plants, and vehicle and marine engines to produce less harmful emissions (Koyun et al., 2012) [1]; (Samokhvalov et al., 2018) [2]. For modern NG engines, the gas-fuel direction injection (DI) technique benefits the engines with high thermal efficiency and less emission pollutants (Li et al., 2019) [3], and now the direct injection compression ignition (DICI) engines have been a prospective research and development focus since they have high efficiency while producing less emissions (Gogolev and Wallace, 2018) [4]. Sevik et al. (2016) conducted experiments of a single-cylinder engine to compare the direct injection and port-fuel injection of natural gas, and their results showed that the direct injection of natural gas allows for up to a $10 \%$ improvement in full-load power density [5]. Ouellette et al. (2016) described that the high-pressure DI natural gas engines may meet Euro VI emissions regulations. For a natural gas direct injection engine, the natural gas jets directly into the cylinder once a cycle, which means that this gas fuel injection is a pulsed injection [6]. Furthermore, this natural gas direct injection occurs in a very short time of only 2-3 milliseconds. As a result, the natural gas must mix well with the background air inside the cylinder in a limited time just before combustion. Li et al. (2019) built a 3D model coupled with a dual-fuel chemical kinetic mechanism to investigate the direct injection 
natural gas engine emission performance, and they reported that soot and CO emissions could be substantially reduced without penalties in NOx and thermal efficiency by the optimization of natural gas injection timing and proportion [7]. Therefore, the natural gas injection characteristics are important for the engine, and it is crucial to control the pulsed natural gas injection so that the combustible air-fuel mixture is ready for good combustion quality.

For the natural gas direct injection engines, the natural gas injection happens at the end of the compression stroke when the cylinder pressure becomes high enough for ignition. This extremely high backpressure for the direct injection results in the demand for the high injection pressure. Huang et al. (2003) investigated the natural gas direction combustion process based on a rapid compression machine, and they reported that the direct injection high-speed fuel jet leads to faster flame propagation [8]. McTaggart et al. (2015) researched the natural gas DI engine using both experimental and numerical methods, and revealed that as the gas injection pressure rises up to $60 \mathrm{MPa}$, both the engine efficiency and the power rise [9]. Therefore, to gain better engine performance, the natural gas injection pressure needs to be raised for the natural gas DI technique. Shuja and Yilbas (2010) reported that the injector nozzle causes great influence on the gas jet impingement [10]. Correspondingly, the higher gas injection pressure may cause great consequences on the gas fuel injection and the mixing process, which is necessary to be revealed.

To investigate the gas fuel injection performance, generally researchers used optical test devices to observe the gas jet process. Dong et al. $(2017,2018)$ observed the macroscopic structure of under-expanded natural gas jets by using the schlieren imaging technique, and they found that oblique shocks occur, and the jet tip penetration could not be obviously improved by increasing the gas injection pressure [11,12]. Sankesh et al. (2018) captured the growth of the transient jet flow of natural gas from an outward-opening conical nozzle direct injector by high-speed schlieren method, and they proposed a new method to calculate combined penetration for radially spreading gas jets [13]. Ishibashi and Tsuru (2017) adopted a shadowgraphy system to optically observe a natural gas jet and dual-fuel combustion progress in a rapid compression and expansion machine (RCEM), and their results show that the natural gas injection parameters such as the injection time delay and the injection angle cause great influence on jet entrainment [14].

The above literature focus on the high-pressure gas fuel jet progress and show that the high gas injection pressure may cause influence on both the macro and micro characteristics. Selimefendigil and Öztop (2013; 2014; 2019) performed a series of research on pulse jet, and they carried out a numerical study of pulsating rectangular jet impingent to investigate the effects of parameters on the fluid flow and heat transfer characteristics. They reported that the pulsation frequency of the jet has caused influences on heat transfer enhancement [15-17]. Therefore, when natural gas is adopted as fuel, its jet process and characteristic affect the combustion.

Moreover, there is much fundamental research on natural gas combustion based on the optical test rig. Sweeney et al. (2012) used two-component particle image velocimetry (PIV) to measure the non-swirling flame in a turbulent methane/air stratified swirl burner [18]. Wang et al. (2008) conducted a visualization experiment on the combustion characteristics of a natural gas/hydrogen mixture injected into a constant volume vessel [19]. Huang et al. (2013) studied natural gas direct injection combustion on a constant volume vessel by schlieren photography, and they found that natural gas injection mode causes great influence on flame propagation [20]. Hu et al. (2019) studied the injected natural gas flame based on a constant volume vessel, and they found that the injection combustion is random [21]. However, the interaction between the gas jet and its flame is not clear yet.

The above literature focused on the natural gas (methane) combustion performance research. The methane gas premixed flame propagation mechanism has been researched, but most research only explains the even mixed methane-air laminar flame. However, for a practical NG DI engine, the jet process of high-pressure NG into the combustion chamber is dynamic. On the one hand, the NG jet penetrates forward, and on the other hand it 
should suck the air into the jet to form the mixture as soon as possible. Actually, for a high rotation speed DI engine, the time between the NG injection time and the ignition time is so short that it is not easy for the gas jet to form an even air-fuel mixture. The ideal even premixed flame mechanism is not suitable for this high-pressure DI gas jet flame.

Considering the practical application of the high-pressure NG (methane) direct injection, it is necessary for the gas fuel jet to be ignited and propagate stably. Moreover, NG fuel jet is not easy to be ignited by spark plug, and it is ignited by a pilot flame. Thus, the interaction between the high-pressure methane jet and the pilot flame is critical, and we are planning to investigate the interaction mechanism between the gas jet and the flame based on both experiment and numerical simulation in future. The fundamental research of the combustion flame of the high-pressure gas jet is quite insufficient. Thus, it is essential to understand thoroughly the complex high-pressure natural gas jet flow characteristic and its combustion.

This work conducted an optical experimental investigation on the high-pressure methane jet from a single-hole injector, and then its ignition flame propagation performance. The high-pressure methane jet and its flame were visually tested by adopting the schlieren method based on an optical constant volume bomb (CVB) test rig. A digital high-speed camera recorded the methane jet and combustion progress under conditions of different pressures.

\section{Experimental Setup}

In this work, we first built a constant volume bomb (CVB) test rig with visualization windows to investigate the methane gas jet progress and the premixed ignition performance.

\subsection{Test of Methane Gas Jet Penetration}

The methane gas jet experiments were completed on a CVB test rig, as shown in Figure 1. The CVB system, made of steel, is a cuboid with an inner cylindrical bore with a total volume of 13.4 L. The size of the cube CVB was length $\times$ width $\times$ height $=330 \mathrm{~mm}$ $\times 300 \mathrm{~mm} \times 300 \mathrm{~mm}$. A high-pressure single-hole injector with a diameter of $0.3 \mathrm{~mm}$ was located on the top center of the CVB. During the experiments, the CVB cylinder was first filled with air of back pressure $p_{\mathrm{b}}$ from a gas tank, and the methane gas jet test began after $5 \mathrm{~min}$ standing of the total CVB test rig. A serial of optical test devices including a schlieren system and a high-speed camera were used to observe the gas injection process. The gas injection timing was triggered by an electronical control unit (ECU) developed by authors, and set to be synchronous with the camera. The methane injection pressure $p_{\text {injection }}$ was adjusted in range of $0.1 \mathrm{MPa}-30 \mathrm{MPa}$, while the back pressure $p_{\mathrm{b}}$ controlled range of 0.1-5 MPa.

The test apparatus for the CVB test rig is illustrated in detail in our previous published literature (Lei et al., 2019) [22]. For each kind of experiment, the gas jet is tested under varied operation conditions. Table 1 gives the specification of the gas jet test.

Table 1. Specifications.

\begin{tabular}{ccc}
\hline Name & & Specification \\
\hline \multirow{2}{*}{ Injector } & Type & Single-hole nozzle \\
& Open mode & Solenoid valve electronically control \\
& Diameter & 0.3 mm \\
Type & Methane, chemical formula: $\mathrm{CH}_{4}$ \\
Test gas & Purity & $99.999 \%$ \\
& Impurity content & Type \\
& Injection pressure & $\mathrm{H}_{2} \leq 1 \mathrm{ppm} ; \mathrm{N}_{2} \leq 1 \mathrm{ppm} ; \mathrm{O}_{2} \leq 1 \mathrm{ppm} ; \mathrm{H}_{2} \mathrm{O} \leq 1 \mathrm{ppm} ; \mathrm{C}_{2} \mathrm{H}_{6} \leq 1$ \\
Environment gas & $5 \mathrm{MPa}, 10 \mathrm{MPa}, 15 \mathrm{MPa}, 20 \mathrm{MPa}, 25 \mathrm{MPa}$ \\
& Back pressure & $1 \mathrm{MPa}$ \\
& Temperature & $298 \mathrm{~K}$ \\
\hline
\end{tabular}




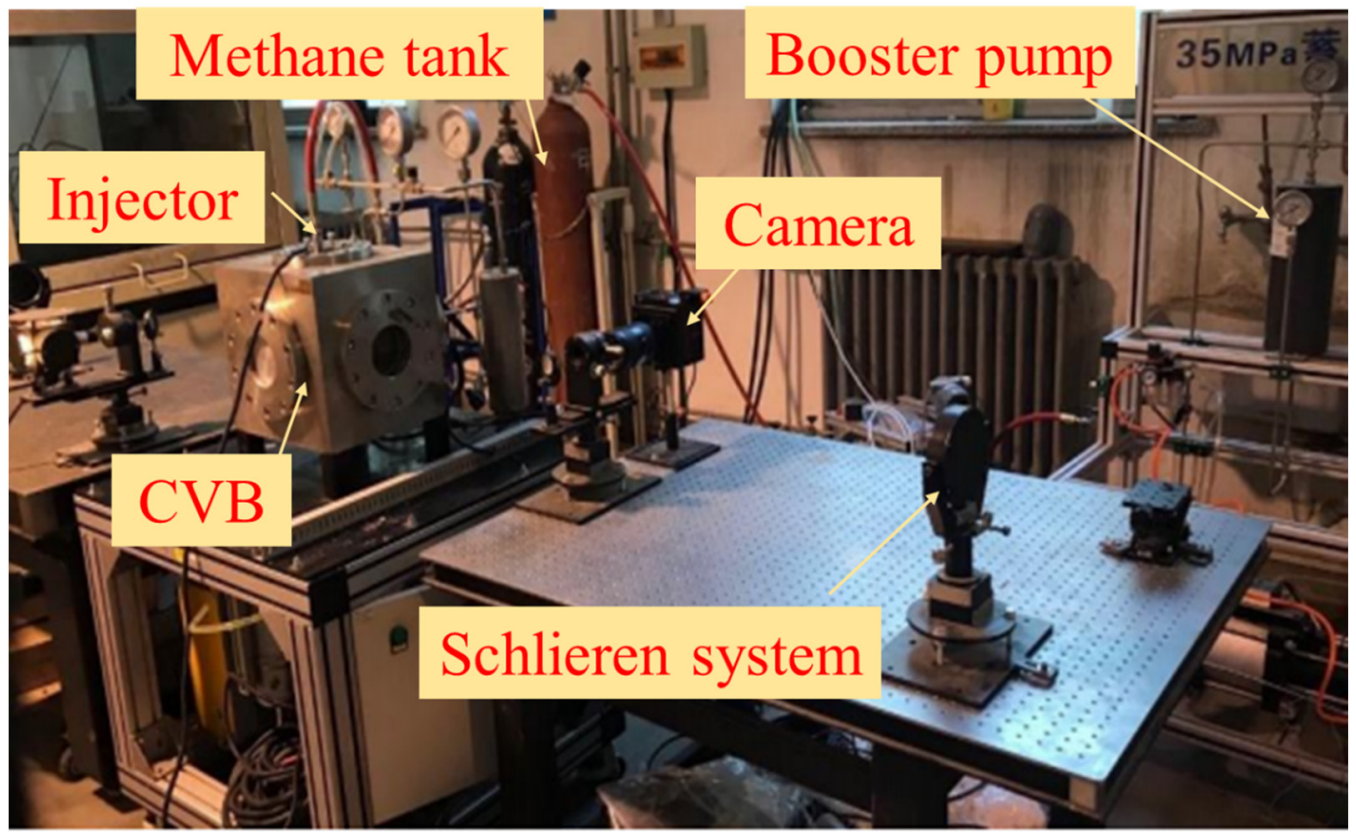

Figure 1. CVB test rig.

\subsection{Test of Methane Gas Jet Premixed Ignition}

For the ignition test, there were two electric electrodes producing sparks to ignite the mixture of methane gas and air. During the methane jet ignition experiments, at the beginning the CVB was provided with air at atmosphere, and an electric heater was used to heat the background air and maintain the gas temperature inside the $\mathrm{CVB}$ at $300^{\circ} \mathrm{C}$. Then, fuel was injected into the CVB chamber through high-pressure injector. After short standing time for the mixing of methane and background air in the CVB, the spark was generated by the electrodes to ignite the premixed methane-and-air mixture. For more detail of the ignition system of CVB test rig please see the authors' published literature (Lei et al., 2021) [23].

To control the injector, the ignition system, the camera, the data acquisition system and the electric heater, we developed an electronically controlled system, and compiled the control driving program using Matlab software. This CVB electronically controlled system can adjust the gas injection pulse, the ignition pulse and synchronically trigger the camera and the spark ignition. Figure 2 gives the details of the methane jet premixed ignition experimental control sequence. The methane gas jets into the chamber with an injection pulse $t_{\text {jet }}$. Generally, there are multiple injections during the premixed process, and there are time gaps among these injections, named as $t_{\text {gap }}$. The total time of all these injections is the premixed jet time, i.e., $t_{\text {premix }}$. After the premixed jet, there is short standing

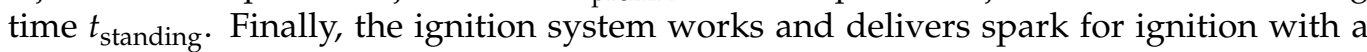
pulse $t_{\text {ignition. }}$. Together with the spark ignition, the camera was synchronously triggered to record the images. During the jet ignition experiments, all the control parameters were arranged by the control system.

\subsection{Images Post Process and Parameter Definition}

The images of gas jet and premixed ignition were post processed, and for more details please see the published literature (Lei et al., 2019) [22]. Figure 3 gives examples of the optical experimental images and the post processed ones. Based on the post processed images, the macro parameters of the methane jet and premixed ignition were defined. The methane gas jet tip penetration $S$ is defined as the maximum vertical distance of the gas jet flow cover contour to the nozzle outlet, and the jet cone cover area is the total area of the gas jet cone. For the jet premixed ignition flame, the center of two electrodes is set as the zero point $\mathrm{O}$. The vertical methane jet is along $y$ direction, and the horizontal direction is $x$. The 
optical results show that the methane jet premixed ignition flame has had a near-spherical shape, i.e., the red rough circle. Based on this post processed data, both the circumference and the area of the rough circle were deduced. Thus, this rough circle in the images has an equivalent radius $r_{\mathrm{u}}$, which is derived based on the circumference and the area.

\section{camera trigger}

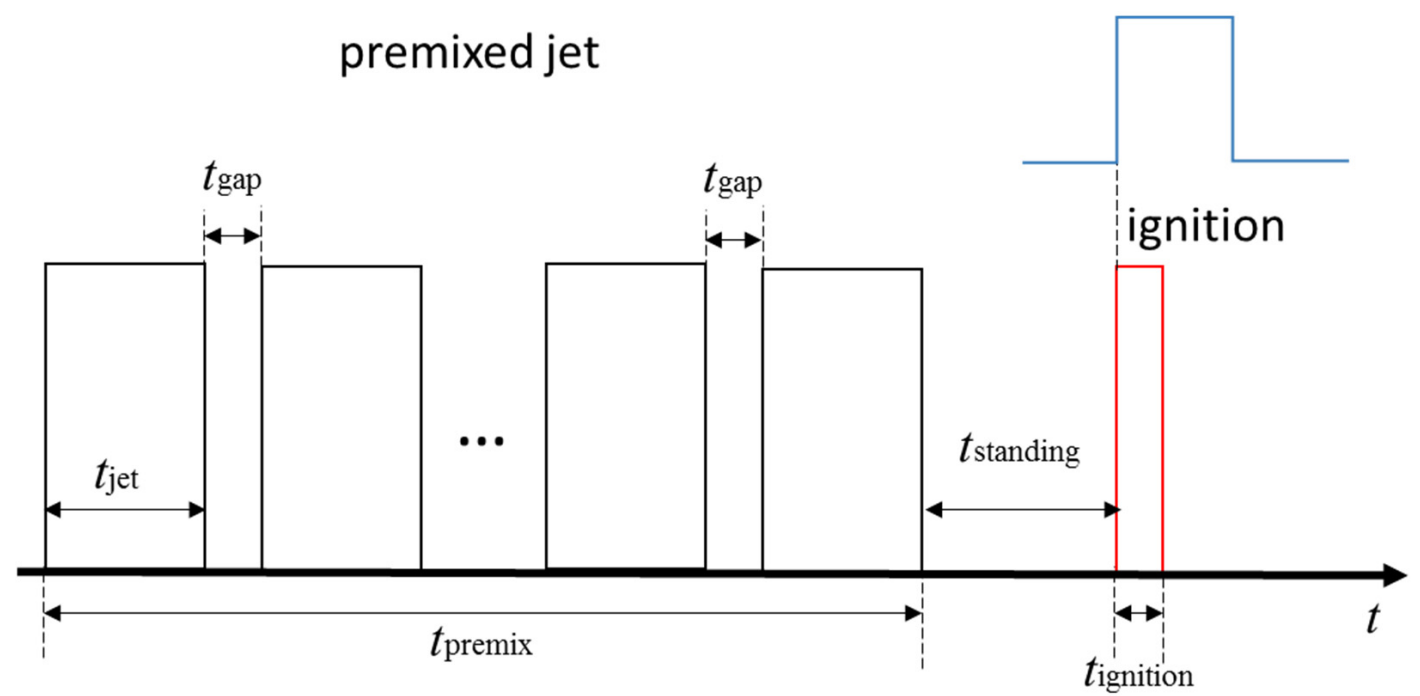

Figure 2. Control sequence of premixed ignition test.

original image

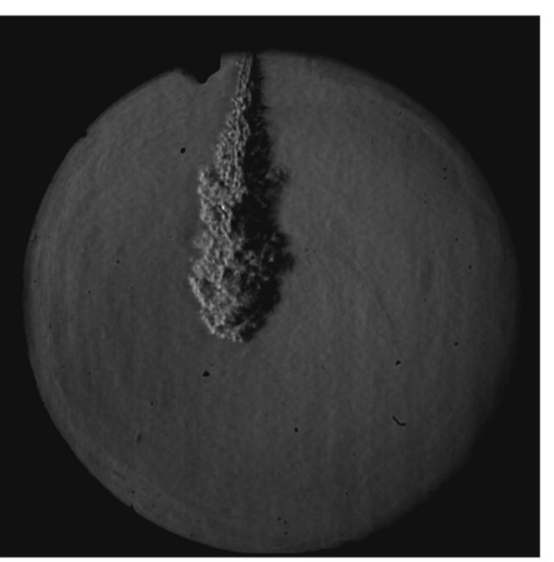

methane jet penetration image outline identification
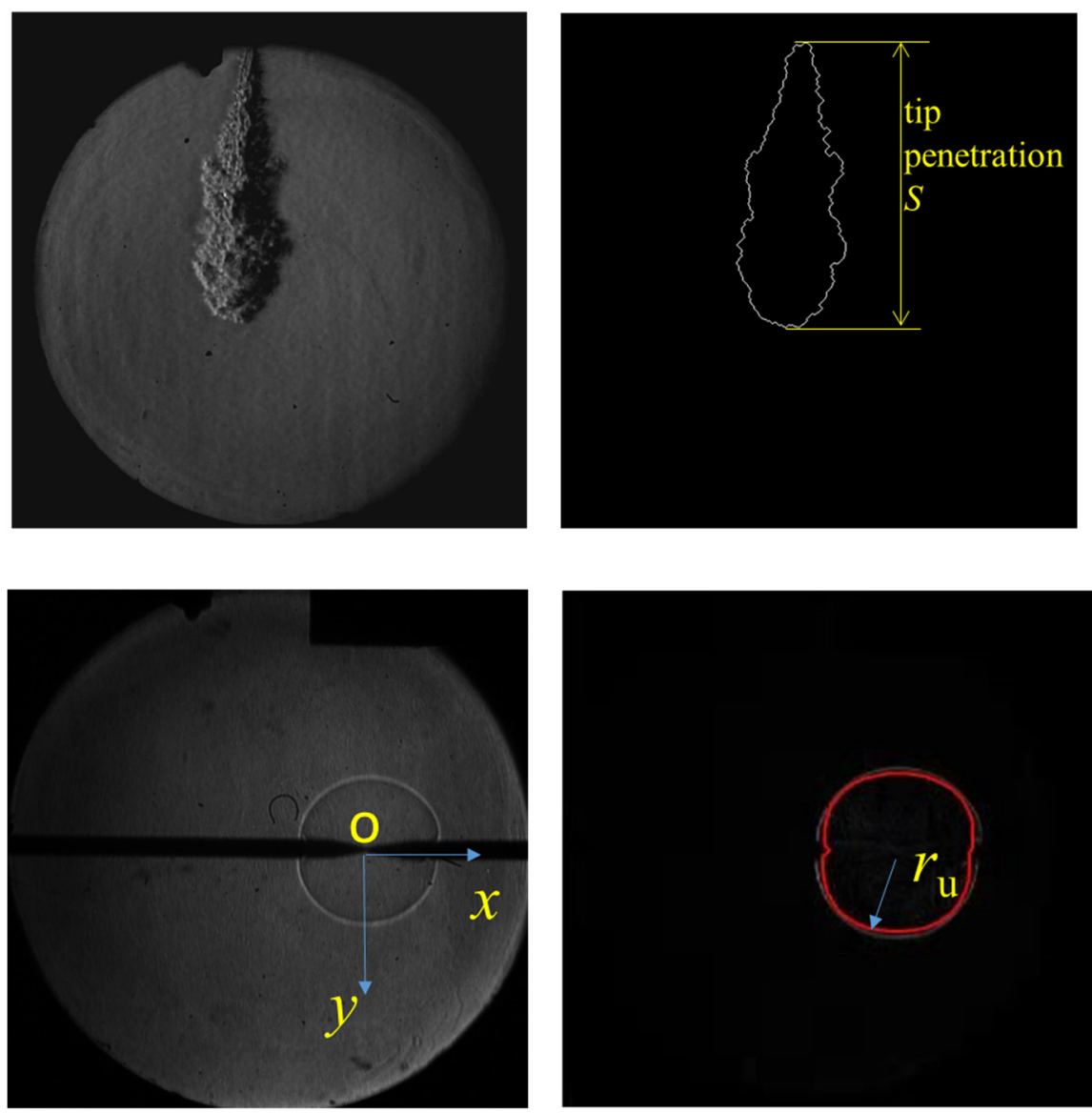

methane jet premixed ignition

Figure 3. Optical image and post process image. 
Therefore, the jet premixed flame velocity $u_{\text {premix }}$ is defined as follows (Miao et al., 2009) [24].

$$
u_{\text {premix }}=\frac{d r_{\mathrm{u}}}{d t}
$$

Here, $r_{u}$ is the radius of the methane jet premixed flame.

Flame stretch rate $\alpha$ is given by Equation (2) (Miao et al., 2009) [24].

$$
\alpha=\frac{d(\ln A)}{d t}=\frac{1}{A} \frac{d A}{d t}
$$

Here, $A$ is the area of the methane jet premixed flame.

Markstein length $L_{\mathrm{b}}$ of flame is an important parameter to represent the flame stability. The Markstein length can be derived by drawing the $u_{\text {premix }}-\alpha$ curve, and it is exactly the slope of the curve.

In addition, for this methane jet premixed ignition experiment, the methane jets into

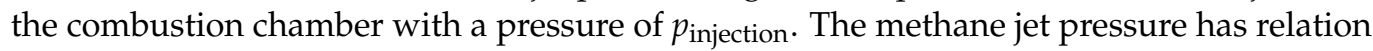
with the equivalence ratio $\phi$ of the methane-and-air mixture, as shown in Equation (3) (Lei et al., 2021) [23].

$$
\phi=\frac{A F_{\text {stoic }} R_{\text {air }}}{R_{\mathrm{CH} 4}} \frac{p}{p_{0}-p}=\frac{A F_{\text {stoic }} R_{\text {air }}}{R_{\mathrm{CH} 4}} \frac{1}{\frac{p_{0} V}{p_{\text {injection }} A_{\text {nozzle }} t_{\text {injection }} \sqrt{k_{\mathrm{CH} 4} R_{\mathrm{CH} 4} T}}-1}
$$

where $A F_{\text {stoic }}$ is the stoichiometric air-fuel ratio; $R_{\mathrm{CH} 4}$ and $R_{\text {air }}$ are the gas constants of methane and air, respectively; and $p_{0}$ is the atmospheric pressure.

\subsection{Uncertainty Analysis of the Optical Experiment}

Based on these optical images, both the methane jet penetration and the jet premixed ignition development processes were analyzed. Furthermore, both the methane jet tip penetration and the jet premixed ignition flame equivalent radius are the practical tested data and the basis of further analysis on other parameters. Furthermore, the jet and combustion experiments were repeated three times for each test condition. The standard deviation method was used for the resulting three sets of test data to complete the uncertainty analysis of the jet and premixed flame propagation characteristics.

The average of the optical test data $\bar{X}$ is defined as

$$
\bar{X}=\frac{\sum_{i}^{n} X_{i}}{n}
$$

where $n$ is the number of the measurements, $X_{i}$ is the measurement result, and here $X i$ respectively represents the methane jet tip penetration $S$ and the methane jet premixed ignition flame equivalent radius $r_{\mathrm{u}}$.

The standard deviation $S D$ is defined as follows:

$$
S D=\sqrt{\frac{\sum_{i=1}^{n}\left(X_{i}-\bar{X}\right)^{2}}{n}}
$$

\section{Results and Discussion}

Figure 4 gives the experimental results of $p_{\text {injection }}=10 \mathrm{MPa}$ and $p_{\mathrm{b}}=1 \mathrm{MPa}$. Once the methane gas comes from the nozzle, it travels directly from the CVB top to the bottom. The front of the methane gas jet continues expanding while the tail end is gradually fuzzy. The gas jet has a shape of cone. 


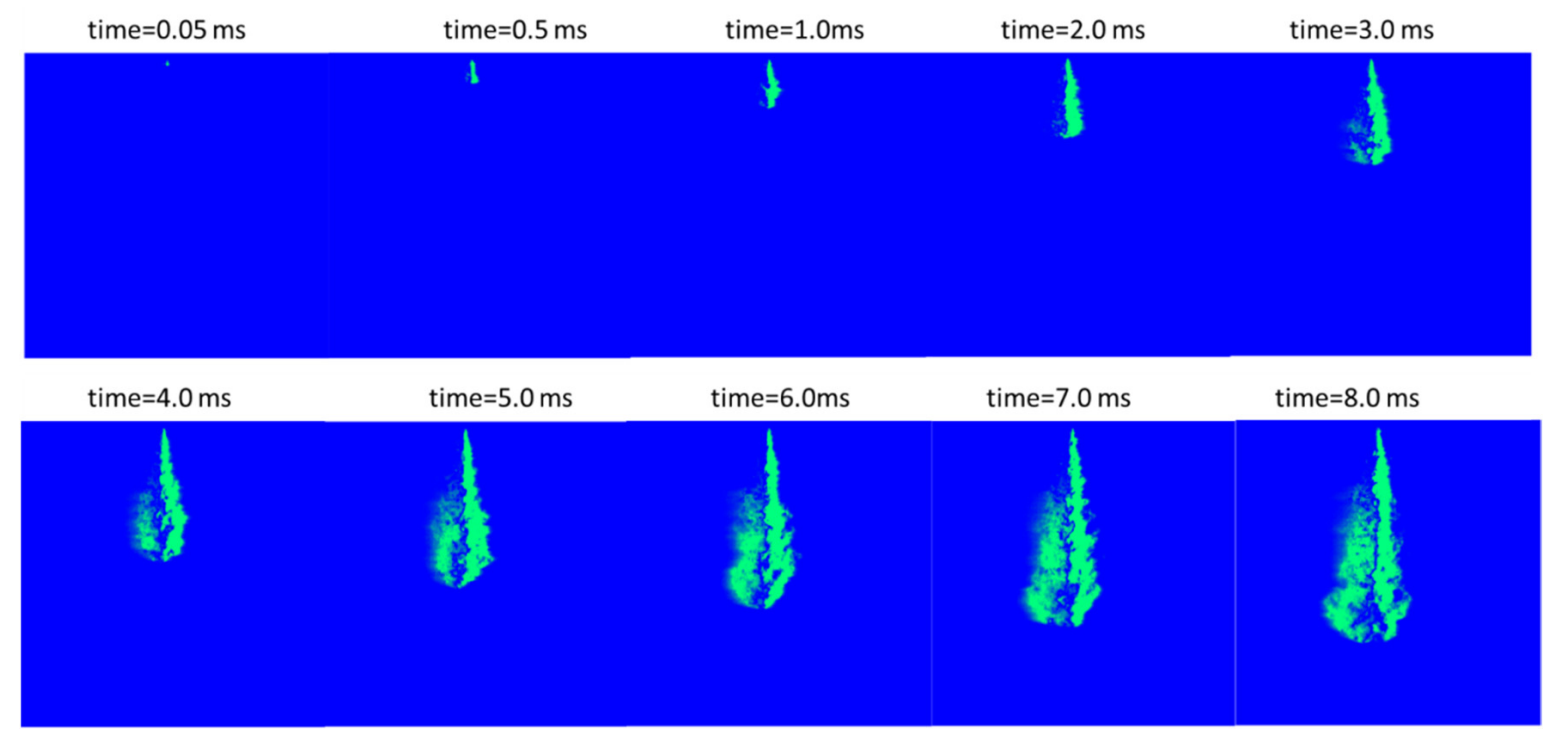

Figure 4. Methane gas jet process.

Figure 5 presents methane gas jet penetration characteristics under condition of $p_{\text {injection }}=10 \mathrm{MPa}, p_{\mathrm{b}}=1 \mathrm{MPa}$. Here, the gas jet tip penetration is acquired based on the optical images, while the methane gas jet penetration velocity is the derivative of the jet tip penetration. It shows that the jet penetration velocity curves may be divided into two stages with a turning point $t_{\text {turning }}$ (here nearly $t_{\text {turning }}=1.8 \mathrm{~ms}$ ). The results reveal that the gas jet penetration has a two-stage feature. The methane gas jet travels at a faster speed during the unstable stage I than that during stable stage II. In addition, the injection pressure causes influences on the methane gas jet penetration distance. Figure $5 \mathrm{~b}$ gives the average gas jet penetration velocity, and it shows that the gas jet penetration velocity tends to increase as the injection pressure increases. In addition, the velocity curve clearly illustrates the gas jet two-stage characteristic as even the injection pressure changes. Figure 5a,c shows the methane gas jet tip penetration and the jet cone area, respectively, and the results reveal that both increase against the time. Figure 5a shows that the jet penetration curves for varied injection pressure tend to coincide with each other at the very beginning of jet $(<0.5 \mathrm{~ms})$, and they separate during the main jet process. Similarly, the jet cone area curves for different injection pressure also have this overlap behavior at the very beginning. For the high-pressure methane jet, the gas flow velocity at the injector nozzle outlet reaches its local sonic speed (Dong et al., 2017; Lei et al., 2019). Thus, for this test, the methane jet velocity at the nozzle outlet is the same, i.e., the local sonic speed, even the injection pressure varies. The methane jet initial energy, i.e., the jet kinetic energy $\frac{1}{2} m v^{2}$ at the nozzle outlet depends on both the methane jet mass $m$ and its jet velocity $v$. The gas jet mass $m$ is relatively much smaller than the gas jet velocity $v$. Moreover, the kinetic energy is property of the first order of the jet mass but the square of velocity. Thus, the velocity causes dominant effect on the jet kinetic energy. As a result, the methane jet energy almost maintains stability for different high injection pressure, which results in the similar jet penetration and jet cone area, as the injection time is smaller than $0.5 \mathrm{~ms}$. Once the jet moves forward and gets farther and farther from the nozzle outlet, the environmental air causes resistance on the methane jet so that the jet slows down and can no longer maintain the sonic speed. In addition, both the jet penetration and jet cone are curves that tend to increase as the injection pressure rises, which reveals that the injection pressure causes influence on the methane jet performance. 


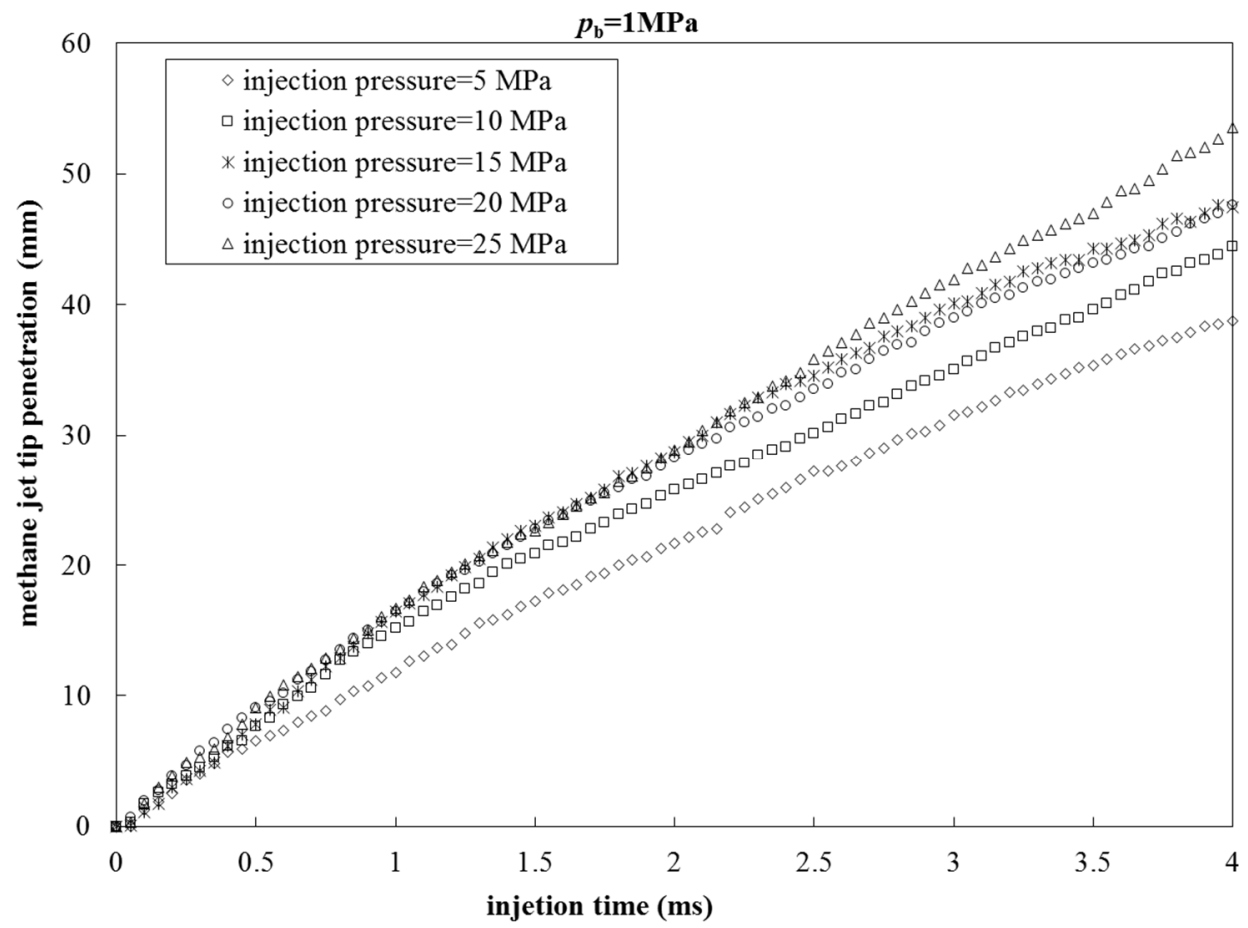

(a) Jet tip penetration

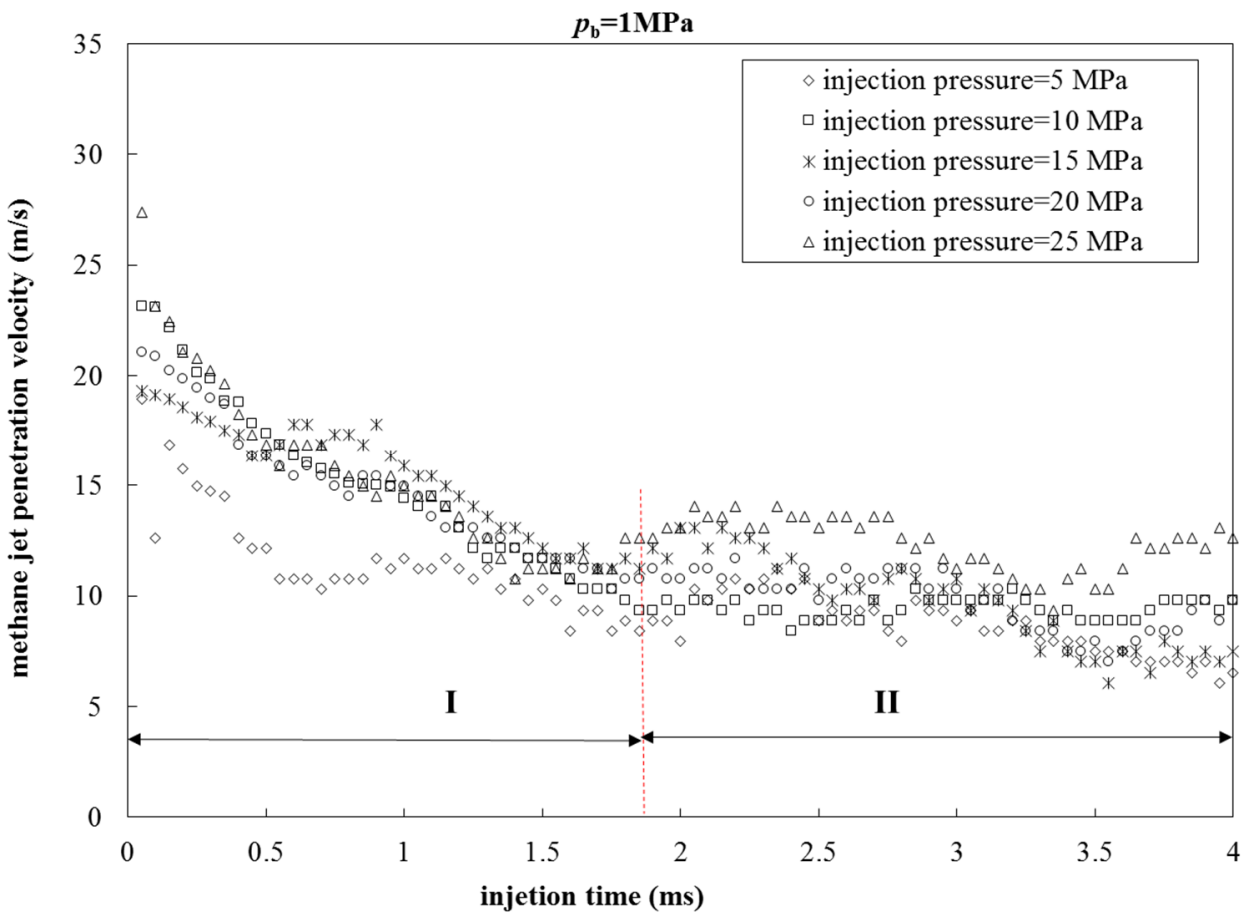

(b) Jet penetration velocity

Figure 5. Cont. 


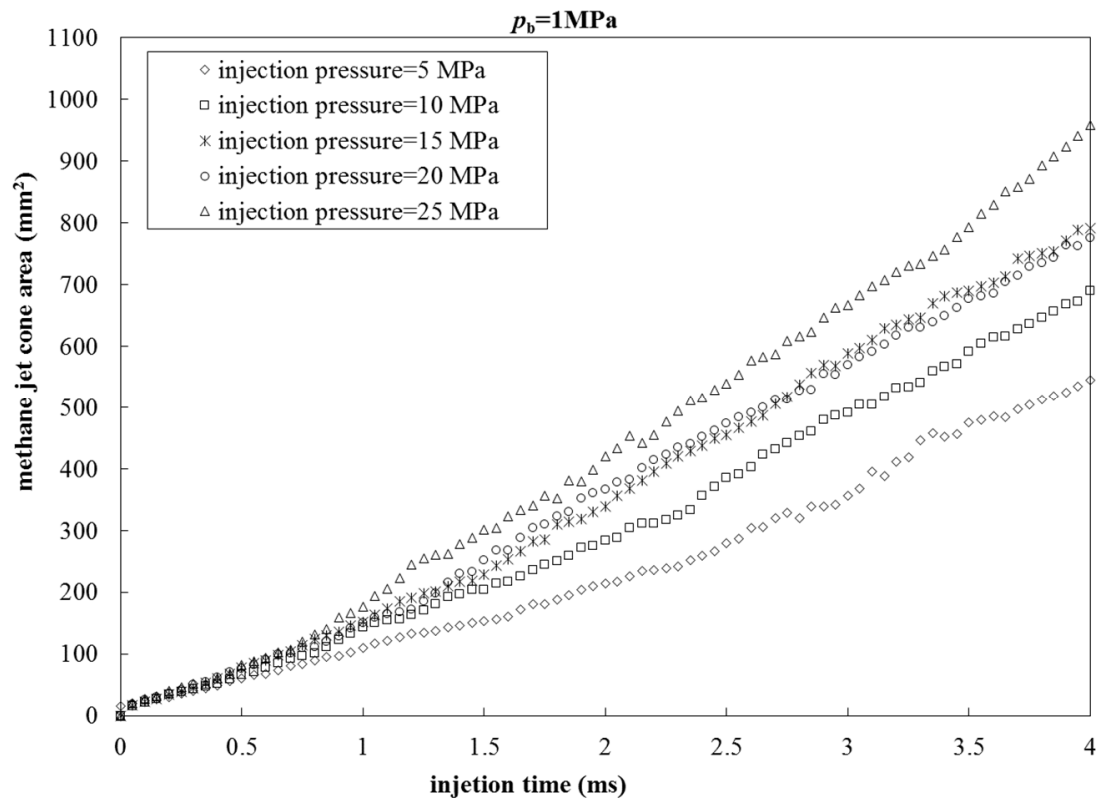

(c) Jet cone area

Figure 5. Two-stage feature of methane jet.

To illustrate the effect of the injection pressure on the methane jet, Figure 6 gives the relation of the methane gas jet performance against the injection pressure. It shows that the methane gas jet characteristic parameters have different changing rate for these two stages of the methane jet. Figure $6 a$ is the methane jet penetration speed, and it slightly increases as the injection pressure rises. Moreover, the injection pressure causes great effects on jet tip penetration and jet cone area for different stages, as shown in Figure $6 \mathrm{~b}, \mathrm{c}$. During stage I (time $=0.5 \mathrm{~ms}, 1 \mathrm{~ms}$ ), as the injection pressure increases, both the jet penetration distance and the jet cone area remain stable. During stage II (time $=2 \mathrm{~ms}, 3 \mathrm{~ms}, 4 \mathrm{~ms}$ ), both the jet penetration distance and the jet cone area linearly increase with the increase in the injection pressure. In addition, the rising rate is greater for higher injection pressure. Furthermore, the rising injection pressure also influences the deviation of methane jet penetration. Figure $6 \mathrm{~d}$ presents the standard deviation of the methane jet penetration under conditions of different injection pressure. The standard deviations are distributed in the shadow area of the figure, and they have a descending tendency as the injection pressure rises. As the injection pressure increases, the methane density at the nozzle jet rises correspondingly, thus the methane jet energy increases, which may result in more stable jet to reduce the measure deviation of the optical test. 


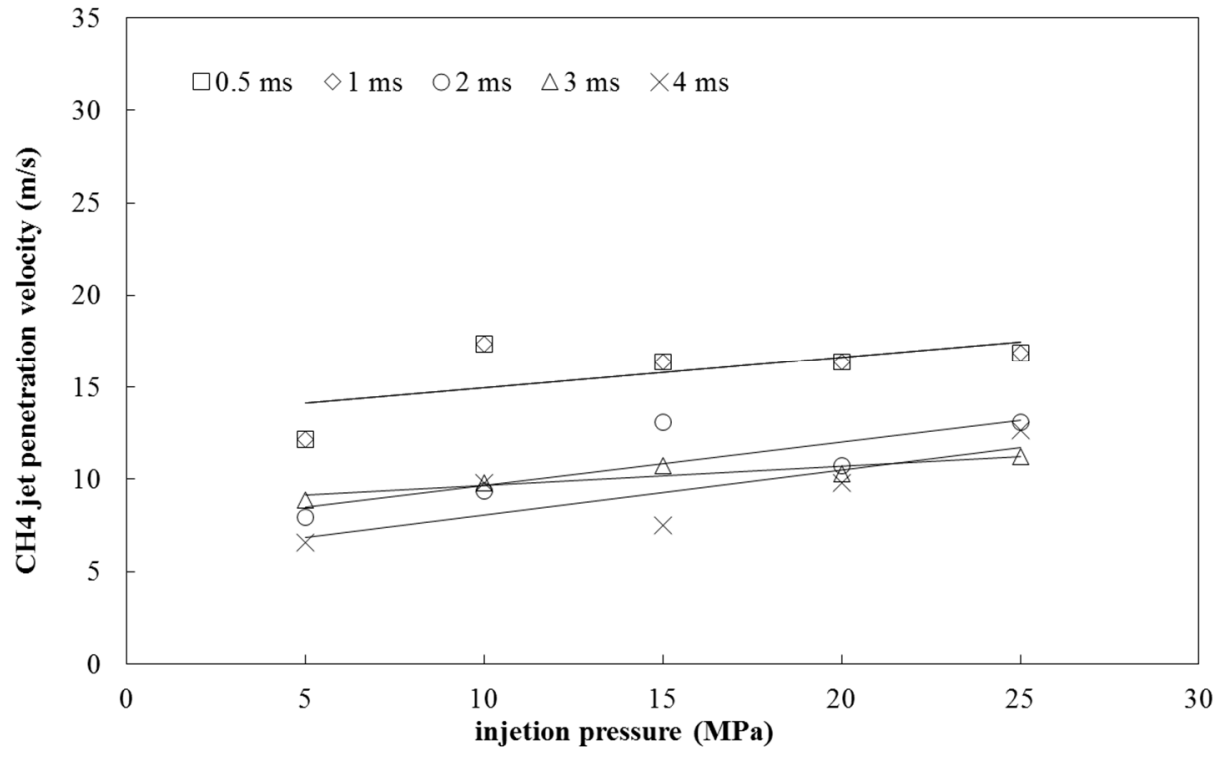

(a) Jet penetration velocity

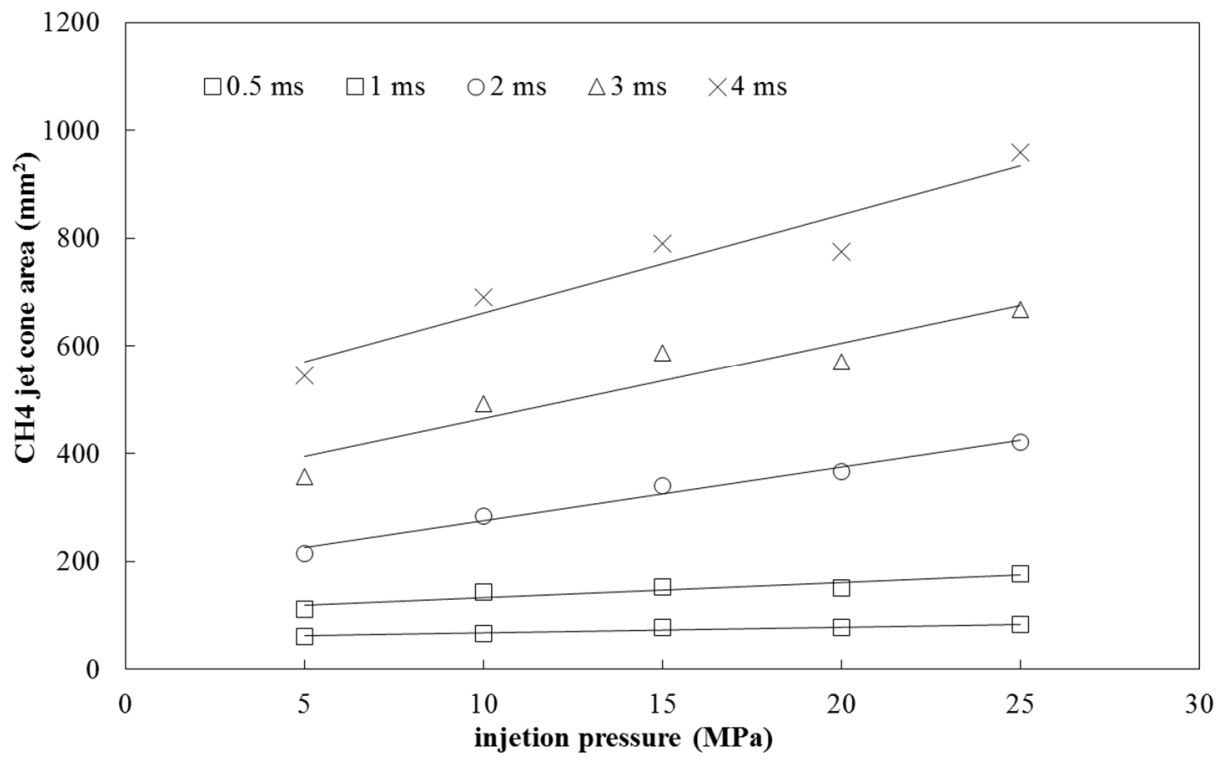

(b) Jet cone area

Figure 6. Cont. 


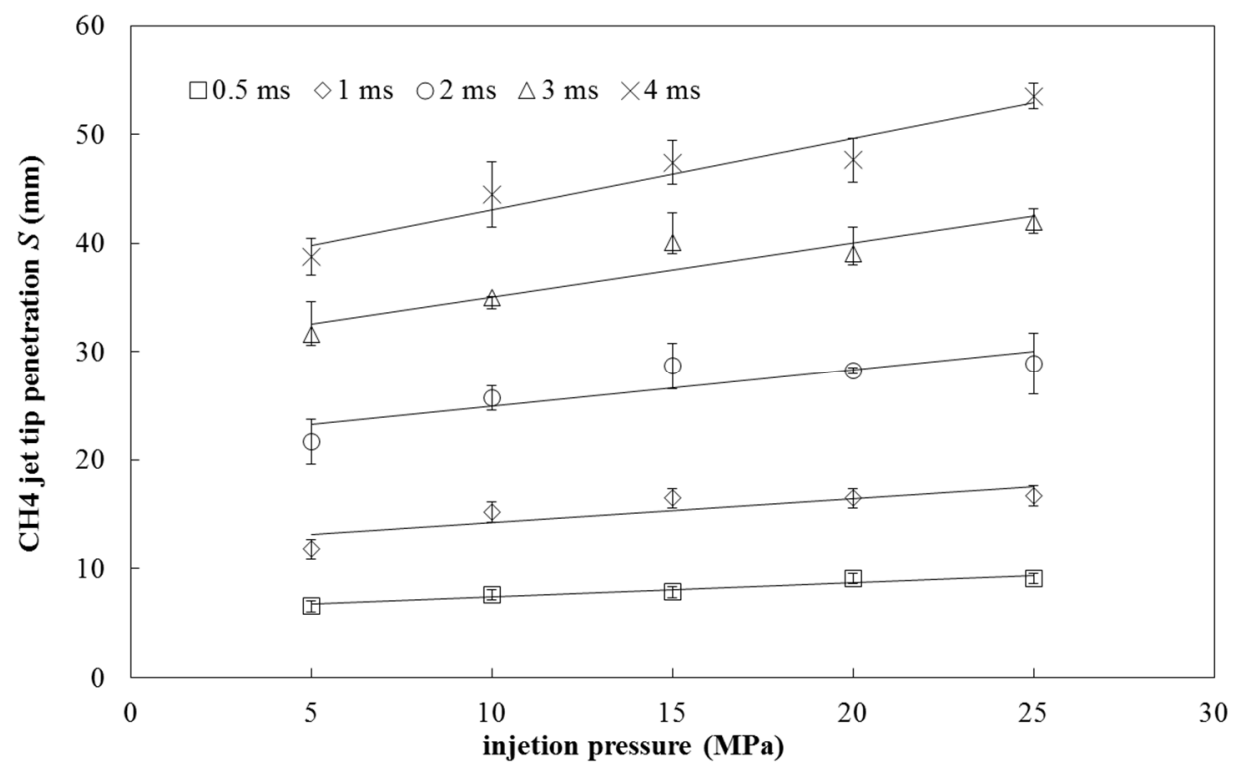

(c) Jet tip penetration

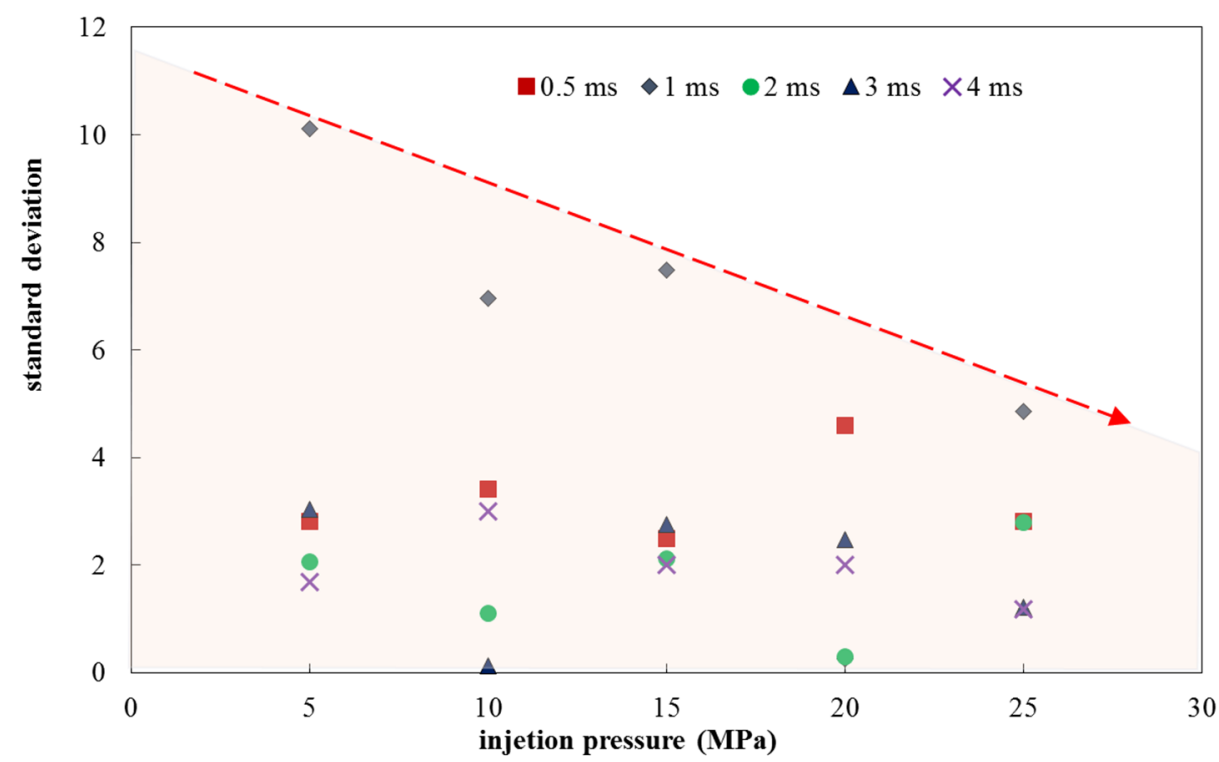

(d) Standard deviation

Figure 6. Effect of injection pressure on gas jet spray penetration distance.

Figure 7 gives the original optical images of the methane jet premixed ignition flame propagation process under condition of methane jet pressure $=12 \mathrm{MPa}$ and back pressure $=0.1 \mathrm{MPa}$. The injector nozzle locates at the top of the CVB combustion chamber. The images of the methane jet premixed flame show that after the spark occurs (time $=0 \mathrm{~ms}$ ), an approximately spherical flame appears, and it propagates outwards. During the early propagation process, the flame maintains a shape of nearly a ball. However, the flame shape becomes stretched as it reaches close to the CVB chamber wall. This out-of-ball distortion of the premixed flame is caused by the reflection of the wall once the flame front moves close to the wall. As the ball-shaped flame penetrates outwards, the flame compresses the environment air, and it may induce waves. Once the penetration wave meets the solid wall, a reflection wave occurs and returns, resulting in a stretching effect on the premixed flame, which induces the flame distortion. 

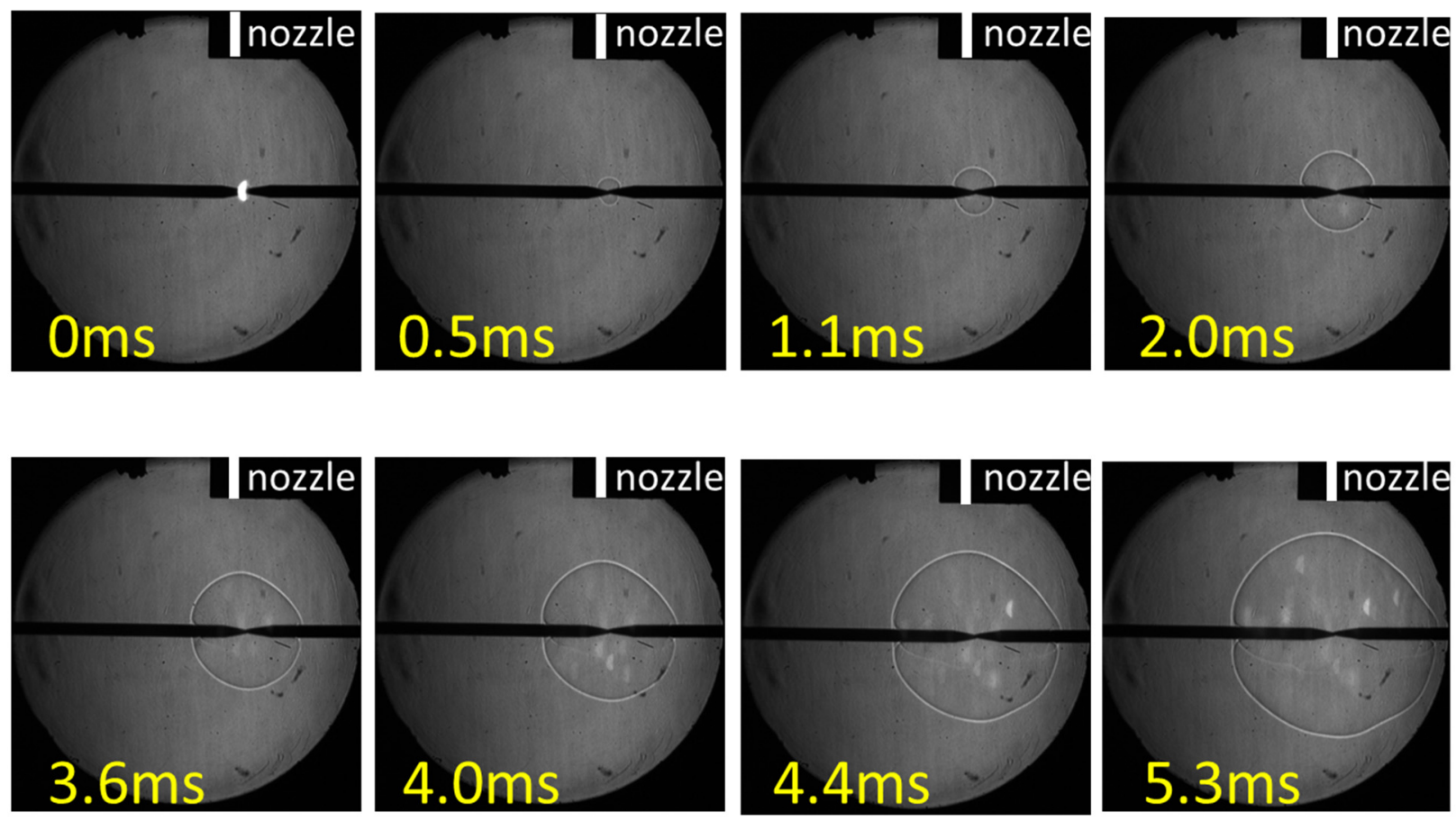

Figure 7. Images of methane premixed ignited flame.

Figure 8 shows the results of the methane jet premixed flame propagation characteristic. Figure 8 a shows that the flame penetration distance, i.e., the equivalent radius $r_{\mathrm{u}}$ linearly increases, and the flame area also increases. Figure $8 \mathrm{~b}$ is the jet premixed flame velocity which is the derivation of the penetration distance and the flame stretch rate. It reveals that the methane jet premixed flame penetrates at an average velocity $u_{\text {premix }}=5.0875 \mathrm{~m} / \mathrm{s}$. The flame stretch rate is higher than 4000 at the beginning and sharply declines to 500. It is worth noting that the shape of the flame begins to deform after time $=4.0 \mathrm{~s}$ in Figure 7 . Once the out-of-ball distortion of the premixed flame occurs, the laminar flame cannot maintain stability. Thus, to deduce Markstein length $L_{b}$ based on the relationship between the jet premixed flame velocity and the flame stretch rate, the data of time $\leq 4.0$ marked by red is adopted in Figure 8c. There is a linear fit between the jet premixed flame velocity and the flame stretch rate, and this slope of this linear fitting is Markstein length $L_{b}$, here $L_{b}=-0.0005$. Markstein length reflects the stability of the premixed flame. Positive value of Markstein length $L_{b}$ indicates that the flame speed decreases with the increase of flame stretch rate, but negative value means that the flame speed increases with the increase of flame stretch rate (Bradley et al., 1996) [25]. Since $L_{b}<0$, the methane jet premixed flame is an unstable flame. If any kind of protuberances appear at the flame front, the flame speed at flame protruding positions will be increased, and therefore the instability of flame increases. 


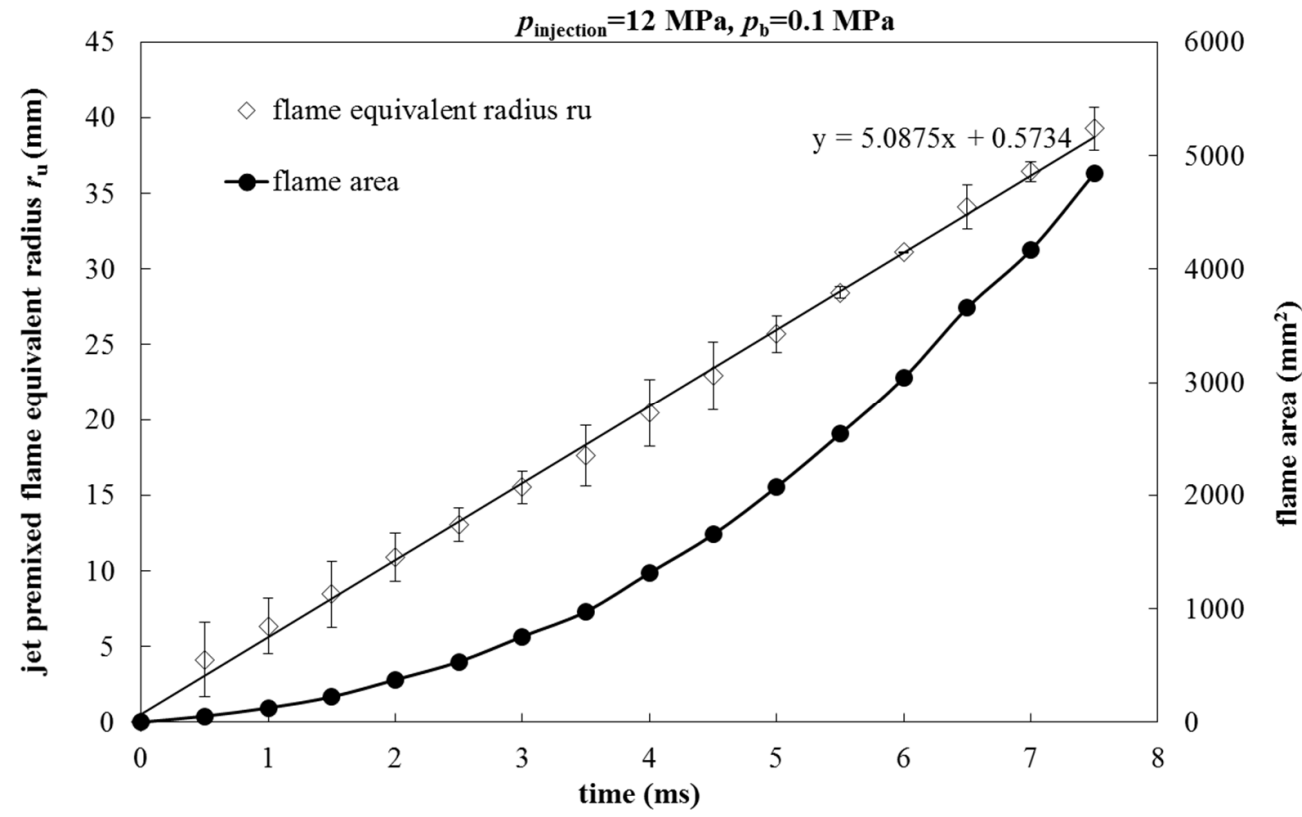

(a) Flame equivalent radius and flame area

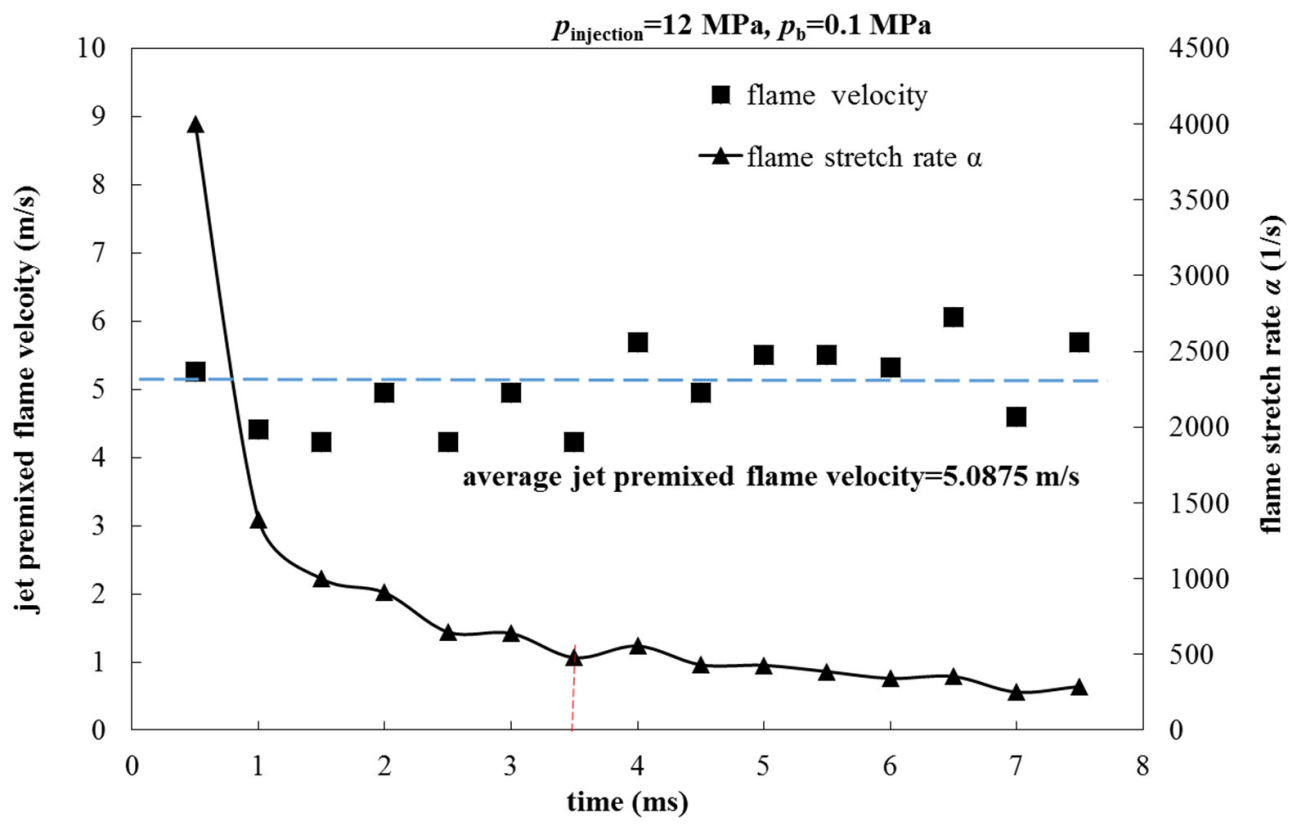

(b) Flame velocity and flame stretch rate

Figure 8. Cont. 


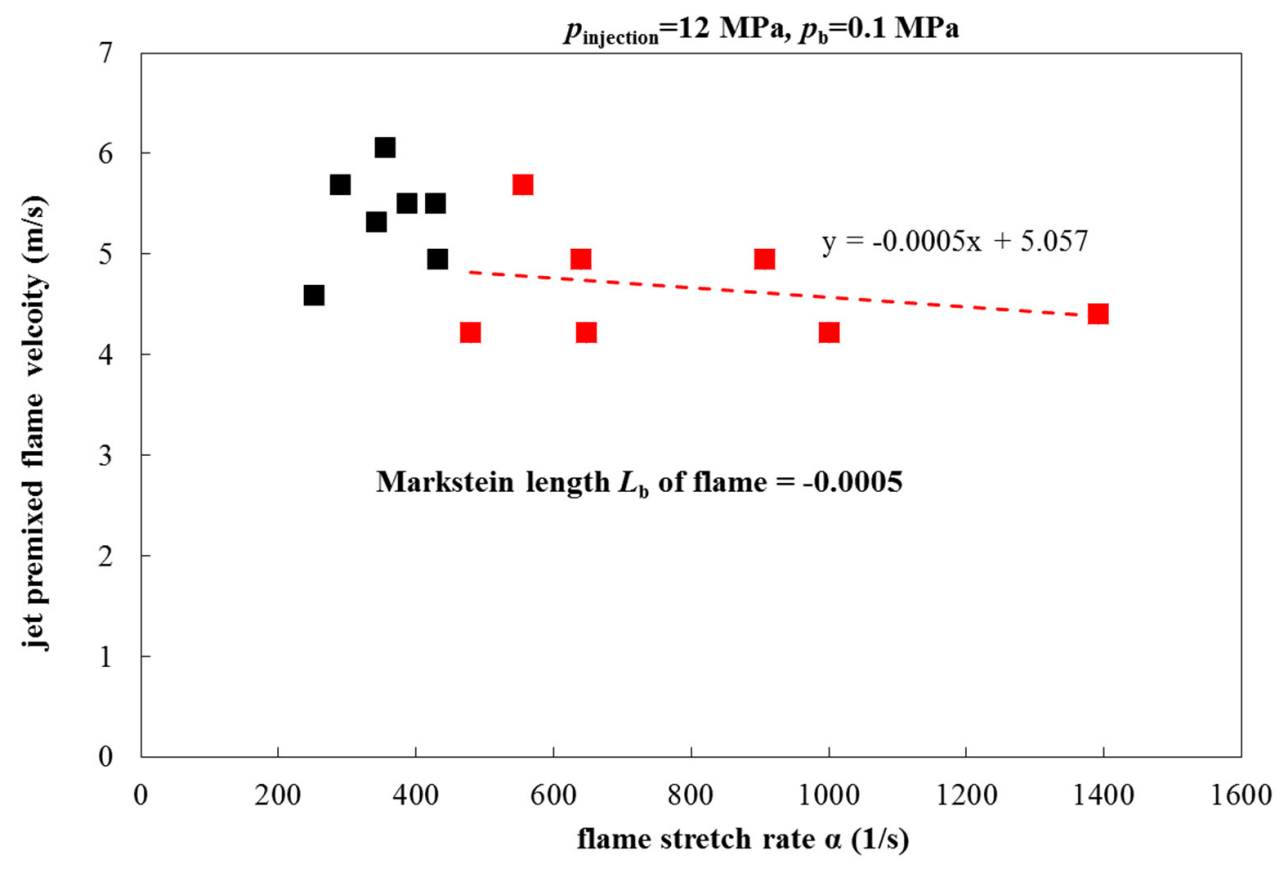

(c) Flame velocity

Figure 8. Methane jet premixed flame propagation characteristic.

For the methane jet premixed ignition test, before ignition there is standing time for the premix of the methane and air. Figure 9 gives the results of the methane jet premixed ignition test under condition of varied standing time. All the methane jet premixed ignition flame propagation distance curves rise with the increase in time. For different varied standing time, at first the flame velocity increases with the increase in the standing time, then it tends to be constant, almost equal to the average flame speed of $4.13 \mathrm{~m} / \mathrm{s}$. For this jet premixed flame, too short of time is not good for the mixing process of the gas fuel and background air. Therefore, in this work the standing time is set to $4 \mathrm{~s}$.

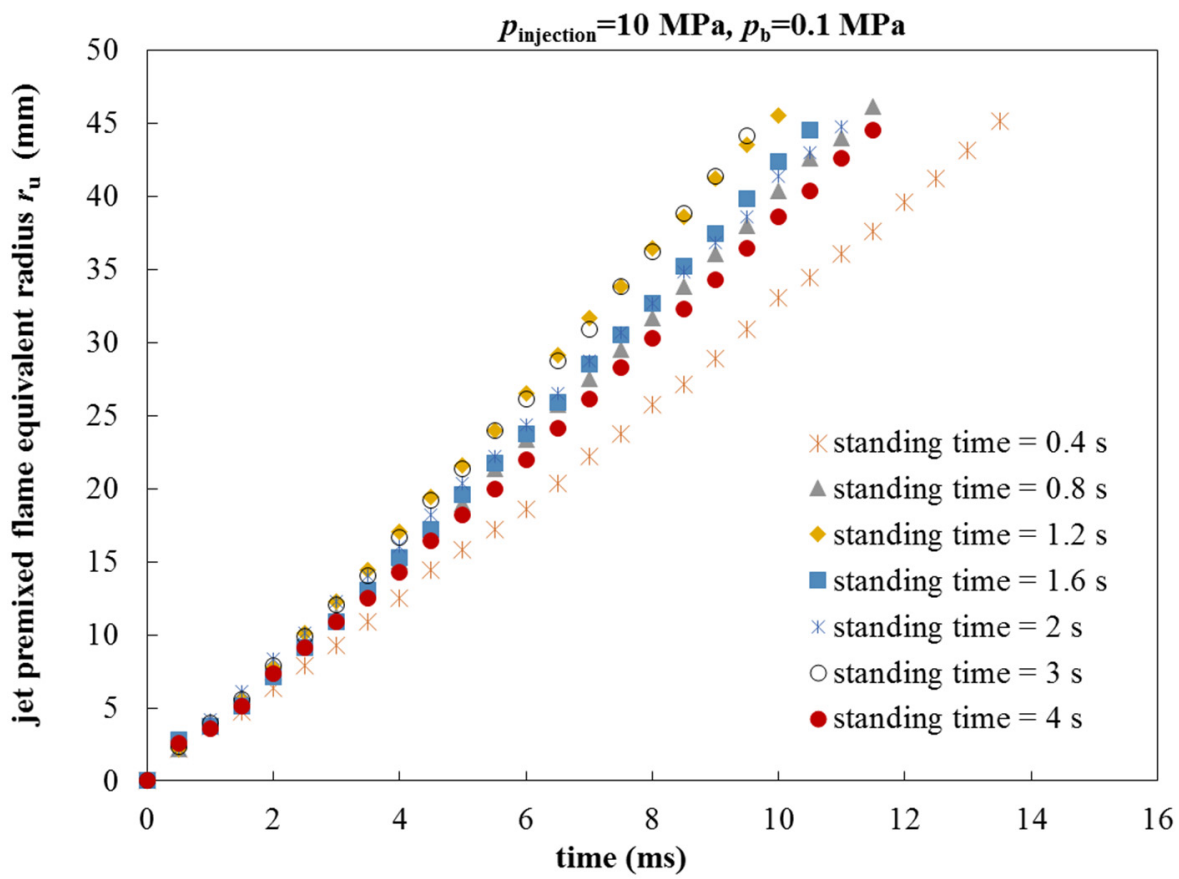

(a) Flame equivalent redius

Figure 9. Cont. 


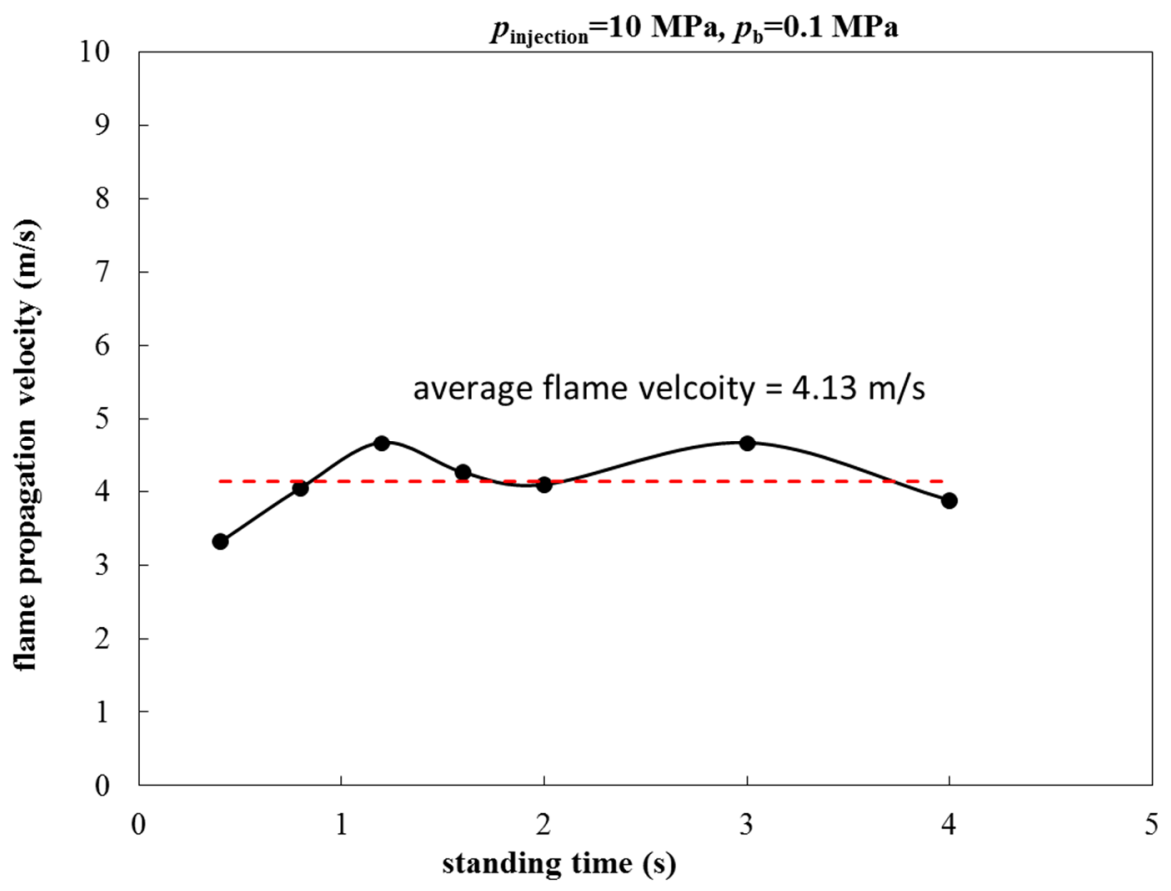

(b) Flame velocity

Figure 9. Effect of standing time on methane jet premixed ignition flame.

Figure 10 presents the effect of the equivalence ratio on the methane jet premixed ignition flame under condition of methane jet pressure $=10 \mathrm{MPa}$ and back pressure $=0.1 \mathrm{MPa}$. Figure 10a gives the flame propagation distance, and it shows that all these curves linearly rise. Based on the ball shape of the flame and the linear feature of the flame propagation distance, it reveals that this high-pressure methane jet premixed flame can be considered as a laminal combustion.

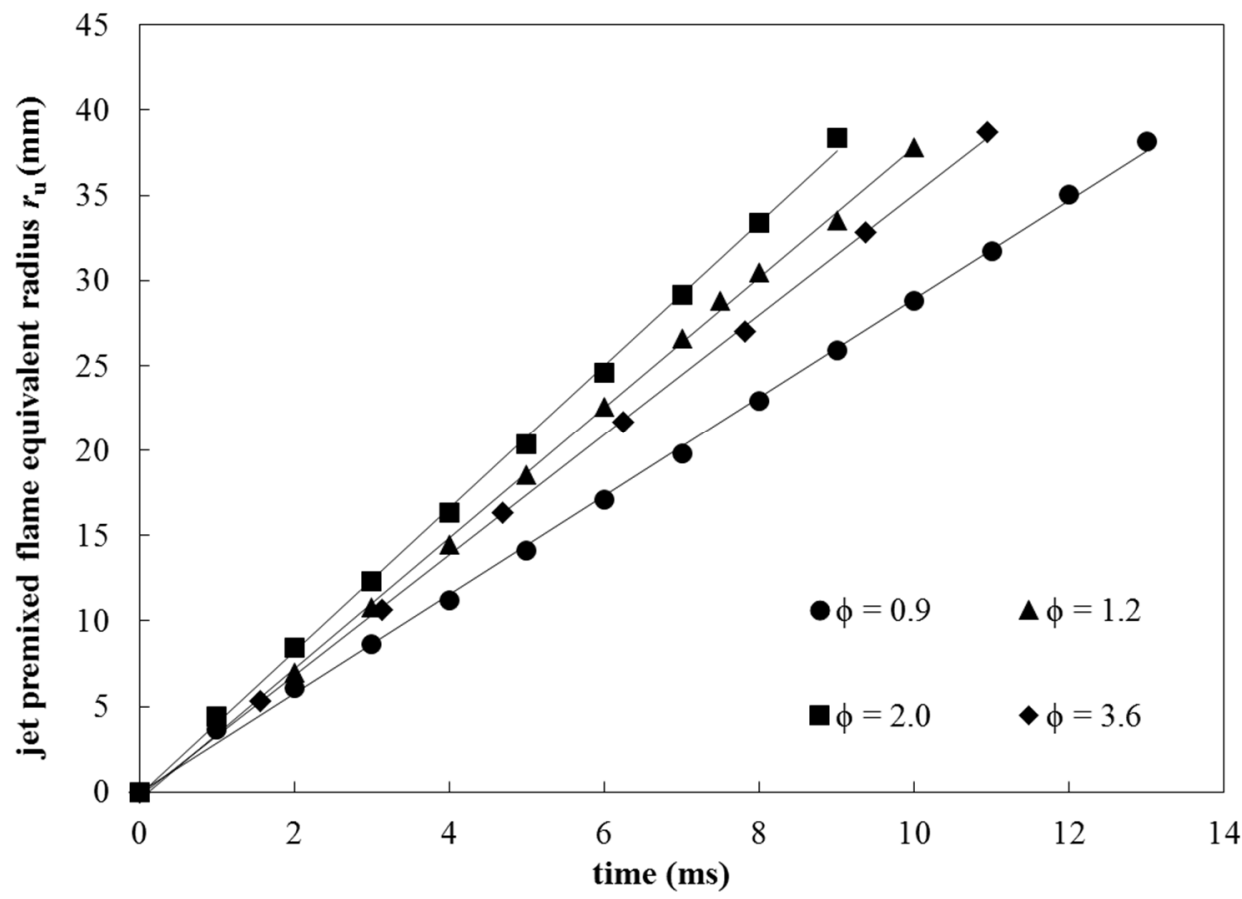

(a) Flame equivalent radius

Figure 10. Cont. 


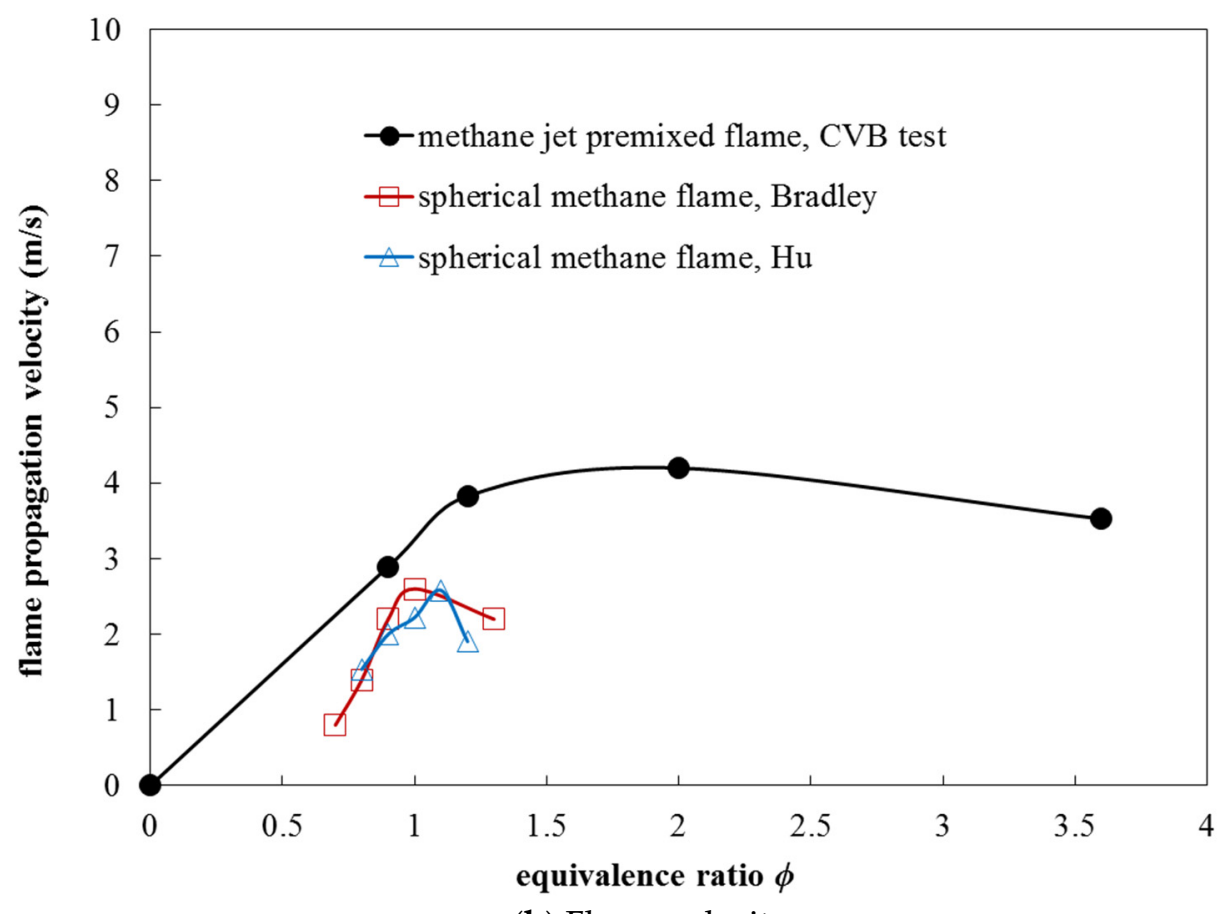

(b) Flame velocity

Figure 10. Effect of equivalence ratio on methane jet premixed ignition flame.

Figure 10b gives the comparison between the methane jet premixed flame and other spherical methane flames (Bradley et al., 1996) [25], (Hu et al., 2019) [21]. It shows that the methane jet premixed flame has greater propagation velocity than those spherical methane flames. This is because the high-pressure methane jet has short mixing time before ignition, but other data are the combustion results of the well-blended methaneair flames. In addition, all the curves demonstrate that the equivalence ratio has great influence on the flame propagation velocity. As the equivalence ratio $\phi$ increases, all the flame propagation velocity curves first go up and then tend to decrease. There is a peak of all these flame propagation velocity curves. As for the spherical methane flame of both Bradley and $\mathrm{Hu}$ data, the peak almost locates at $\phi=1$. However, this flame propagation velocity peak moves to greater equivalence ratio $\phi$, as for the methane jet premixed flame in this CVB test, which reveals that the peak flame velocity occurs nearly at $\phi=2$ for this case. As the equivalence ratio $\phi$ increases, i.e., the methane-and-air mixture in the CVB becomes richer, the high-speed methane jet sucks the environmental air into the jet to form the combustible methane-air mixture while the jet continues to propagate. In addition, the even methane-air mixture for spherical laminar flame needs enough time to form. However, the methane jet only experiences short standing time before ignition. Therefore, this methane jet premixed flame is actually a partial premixed flame.

The methane jet pressure also causes influences on the jet premixed flame, as shown in Figure 11. All the flame equivalent radius curves linearly rise against the jet time, and the expression formal of each fitting line is present too. The value of the slope of the fitting line is exactly the flame velocity. Furthermore, as the injection pressure rises, the jet premixed flame equivalent radius increases, which means the flame velocity also rises. For the flame velocity, it linearly increases with the increase in the injection pressure. That is to say, the higher methane injection pressure, the faster the jet premixed flame velocity. As for the same injection duration, as the injection pressure rises, the total methane jet mass becomes larger due to the increasing density. This higher injection pressure results in greater equivalence ratio, and thus the flame velocity increases correspondingly. 


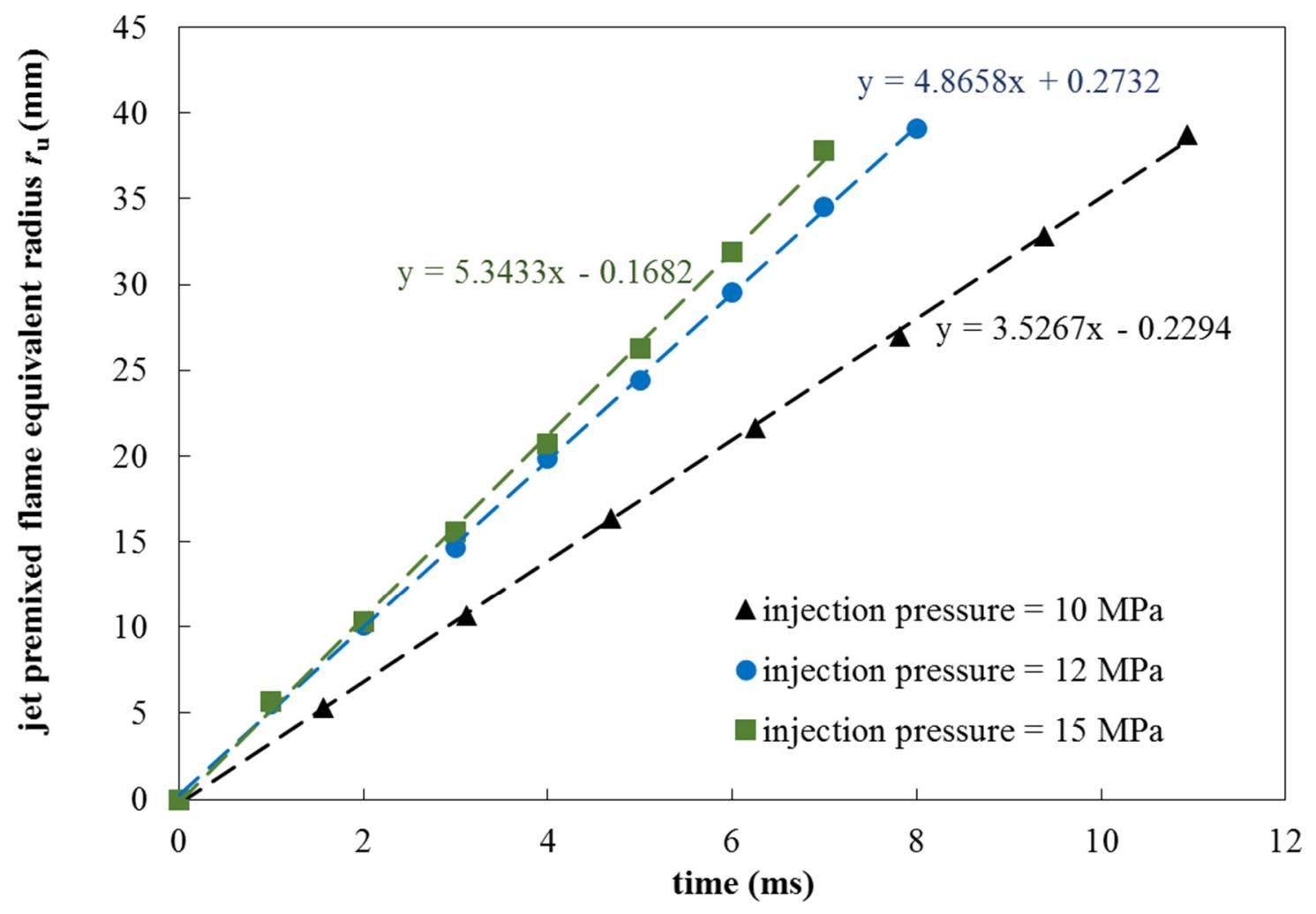

Figure 11. Effect of injection pressure on methane jet premixed flame.

\section{Conclusions}

The methane gas jet has a two-stage feature in time dimension. The methane gas jet travels at a faster speed during the unstable stage I than that during stable stage II. In addition, the injection pressure causes influences on the methane gas jet. During both stage I and II, the injection pressure has a certain degree of influence on the methane jet penetration speed, but the influence is insignificant. During stage I, as the injection pressure increases, both the jet penetration distance and the jet cone area remain stable. During stage II, both the jet penetration distance and the jet cone area linearly increase with the increase in the injection pressure. Moreover, the rising rate is greater for higher injection pressure.

The methane jet premixed flame has nearly a spherical shape, and its equivalent radius linearly increases. The methane jet premixed flame area also increases while the flame stretch rate declines. The Markstein length of the jet premixed flame $L_{b}$ is below zero. The methane jet premixed flame is a stable flame.

The methane jet premixed flame velocity rises as both the standing time and equivalent ratio increase; however, it tends to slightly decline even though those two parameters continue to increase. The methane jet premixed flame is a partial premixed flame, and its propagation velocity is greater than that of the spherical laminar flame. Furthermore, the peak of the methane jet premixed flame occurs at greater equivalence ratio $\phi$, i.e., $\phi>2$.

The methane injection pressure causes influences on the jet premixed flame. As the injection pressure rises, the jet premixed flame equivalent radius increases, and the flame velocity linearly increases. The higher the methane injection pressure, the faster the jet premixed flame velocity.

Considering the practical application of the high-pressure NG (methane) direct injection, it is necessary for the gas fuel jet to be ignited and propagate stably. Moreover, the NG fuel jet is not easily ignited by spark plug, and it is ignited by a pilot flame. Thus, the interaction between the high-pressure methane jet and the pilot flame is critical, and we are planning to investigate the interaction mechanism between the gas jet and the flame based on both experiment and numerical simulation in future. 
Author Contributions: Conceptualization, Y.L. and T.Q.; methodology, S.G.; software, L.S.; validation, B.P.; formal analysis, Y.L. and X.A.; investigation, Y.L. and S.G.; resources, B.P.; data curation, L.S.; writing—original draft preparation, Y.L.; writing—review and editing, Y.L.; visualization, X.W.; supervision, T.Q.; project administration, S.G. and L.S.; funding acquisition, Y.L. All authors have read and agreed to the published version of the manuscript.

Funding: This research was funded by the State Key Laboratory of Engine Reliability Foundations grant number skler-201913. And The APC was funded by Beijing University of Technology.

Acknowledgments: We gratefully acknowledge financial support for this work by the State Key Laboratory of Engine Reliability Foundations (skler-201913) and Beijing University of Technology.

Conflicts of Interest: The authors declare no conflict of interest.

\section{Nomenclature}

$\begin{array}{ll}\alpha & \text { flame stretch rate } \\ A & \text { jet premixed ignition flame area } \\ A F_{\text {stoic }} & \text { stoichiometric air-fuel ratio } \\ L_{\mathrm{b}} & \text { Markstein length } \\ p_{\mathrm{b}} & \text { back pressure } \\ p_{0} & \text { atmospheric pressure } \\ R_{\mathrm{CH} 4} & \text { gas constants of methane } \\ S & \text { methane jet tip penetration } \\ t_{\text {ignition }} & \text { pulse width of ignition } \\ t_{\text {premix }} & \text { total time of premix injection } \\ u_{\text {premix }} & \text { jet premixed flame velocity } \\ \phi & \text { equivalence ratio } \\ A_{\text {nozzle }} & \text { nozzle area } \\ k_{\mathrm{CH} 4} & \text { methane adiabatic exponent } \\ p & \text { pressure } \\ p_{\text {injection }} & \text { methane injection pressure } \\ R_{\text {air }} & \text { gas constants of air } \\ r_{\mathrm{u}} & \text { flame equivalent radius } \\ t_{\text {gap }} & \text { time gap among injections } \\ t_{\text {jet }} & \text { pulse width of jet injection } \\ t_{\text {standing }} & \text { standing time between jet and ignition } \\ V & \text { volume of CVB chamber }\end{array}$

\section{References}

1. Koyun, T.; Kunduz, M.; Öztop, H.F.; Ucgul, I. Comparison of purification processes of natural gas obtained from three different regions in the world. J. Nat. Gas Chem. 2012, 21, 61-68. [CrossRef]

2. Samokhvalov, Y.; Kolesnikov, A.; Krotov, A.; Parkin, A.; Navasardyan, E.S.; Arkharov, I.A. Heat transfer in the structure of a spiral-wound heat exchanger for liquefied natural gas production: Review of numerical models for the heat-transfer coefficient of condensation for a hydrocarbon mixture in a horizontal tube. J. Enhanc. Heat Transf. 2018, 25, 109-120. [CrossRef]

3. Li, M.; Wu, H.; Zhang, T.; Shen, B.; Zhang, Q.; Li, Z. A comprehensive review of pilot ignited high pressure direct injection natural gas engines: Factors affecting combustion, emissions and performance. Renew. Sustain. Energy Rev. 2019, 119, 109653. [CrossRef]

4. Gogolev, I.M.; Wallace, J.S. Performance and emissions of a compression-ignition direct-injected natural gas engine with shielded glow plug ignition assist. Energy Convers. Manag. 2018, 164, 70-82. [CrossRef]

5. Sevik, J.; Pamminger, M.; Wallner, T.; Scarcelli, R.; Reese, R.; Iqbal, A.; Boyer, B.; Wooldridge, S.; Hall, C.; Miers, S. Performance, Efficiency and Emissions Assessment of Natural Gas Direct Injection compared to Gasoline and Natural Gas Port-Fuel Injection in an Automotive Engine. SAE Int. J. Engines 2016, 9, 1130-1142. [CrossRef]

6. Ouelette, P.; Goudie, D.; McTaggart-Cowan, G. Progress in the development of natural gas high pressure direct injection for Euro VI heavy-duty trucks. In Internationaler Motorenkongress; Springer Vieweg: Wiesbaden, Germany, 2016; pp. 591-607. [CrossRef]

7. Li, M.; Zheng, X.; Zhang, Q.; Li, Z.; Shen, B.; Liu, X. The effects of partially premixed combustion mode on the performance and emissions of a direct injection natural gas engine. Fuel 2019, 250, 218-234. [CrossRef]

8. Huang, Z.; Shiga, S.; Ueda, T.; Nakamura, H.; Ishima, T.; Obokata, T.; Tsue, M.; Kono, M. Study of cycle-by-cycle variations of natural gas direct injection combustion using a rapid compression machine. Proc. Inst. Mech. Eng. Part D J. Automob. Eng. 2003, 217, 53-61. [CrossRef] 
9. McTaggart-Cowan, G.; Mann, K.; Huang, J.; Singh, A.; Patychuk, B.; Zheng, Z.X.; Munshi, S. Direct Injection of Natural Gas at up to 600 Bar in a Pilot-Ignited Heavy-Duty Engine. SAE Int. J. Engines 2015, 8, 981-996. [CrossRef]

10. Yilbas, B.S.; Shuja, S.Z. Flow Impingement onto a Conical Cavity at Elevated Wall Temperature: Effects of Conical Nozzle Cone Angle and Flow Velocities on Heat Transfer Rates. J. Enhanc. Heat Transf. 2010, 17, 23-43. [CrossRef]

11. Dong, Q.; Li, Y.; Song, E.; Fan, L.; Yao, C.; Sun, J. Visualization research on injection characteristics of high-pressure gas jets for natural gas engine. Appl. Therm. Eng. 2017, 132, 165-173. [CrossRef]

12. Dong, Q.; Li, Y.; Song, E.; Yao, C.; Fan, L.; Sun, J. The characteristic analysis of high-pressure gas jets for natural gas engine based on shock wave structure. Energy Convers. Manag. 2017, 149, 26-38. [CrossRef]

13. Sankesh, D.; Petersen, P.; Lappas, P. Flow characteristics of natural-gas from an outward-opening nozzle for direct injection engines. Fuel 2018, 218, 188-202. [CrossRef]

14. Ishibashi, R.; Tsuru, D. An optical investigation of combustion process of a direct high-pressure injection of natural gas. J. Mar. Sci. Technol. 2016, 22, 447-458. [CrossRef]

15. Selimefendigil, F.; Öztop, H.F. Identification of forced convection in pulsating flow at a backward facing step with a stationary cylinder subjected to nanofluid. Int. Commun. Heat Mass Transf. 2013, 45, 111-121. [CrossRef]

16. Selimefendigil, F.; Öztop, H.F. Pulsating nanofluids jet impingement cooling of a heated horizontal surface. Int. J. Heat Mass Transf. 2014, 69, 54-65. [CrossRef]

17. Selimefendigil, F.; Öztop, H.F. MHD Pulsating forced convection of nanofluid over parallel plates with blocks in a channel. Int. J. Mech. Sci. 2019, 157-158, 726-740. [CrossRef]

18. Sweeney, M.S.; Hochgreb, S.; Dunn, M.J.; Barlow, R.S. The structure of turbulent stratified and premixed methane/air flames I: Non-swirling flows. Combust. Flame 2012, 159, 2896-2911. [CrossRef]

19. Wang, J.; Huang, Z.; Miao, H.; Wang, X.; Jiang, D. Characteristics of direct injection combustion fuelled by natural gas-hydrogen mixtures using a constant volume vessel. Int. J. Hydrogen Energy 2008, 33, 1947-1956. [CrossRef]

20. Huang, Z.; Shiga, S.; Ueda, T.; Nakamura, H.; Ishima, T.; Obokata, T.; Tsue, M.; Kono, M. Visualization study of natural gas direct injection combustion. Proc. Inst. Mech. Eng. Part D J. Automob. Eng. 2003, 217, 667-676. [CrossRef]

21. Hu, E.; Huang, S.; Ku, J.; Huang, Z. Combustion characteristics of natural gas injected into a constant volume vessel. Fuel 2018, 235, 1146-1158. [CrossRef]

22. Lei, Y.; Liu, J.; Qiu, T.; Li, Y.; Wang, Y.; Wan, B.; Liu, X. Gas jet flow characteristic of high-pressure methane pulsed injection of single-hole cylindrical nozzle. Fuel 2019, 257, 116081. [CrossRef]

23. Lei, Y.; Li, Y.; Qiu, T.; Li, Y.; Wang, Y.; Zhang, C.; Liu, J.; Ding, M.; Liu, X.; Peng, G. Effects of high-pressure methane jet on premixed ignited flame in constant-volume bomb. Energy 2020, 220, 119695. [CrossRef]

24. Miao, H.; Ji, M.; Jiao, Q.; Huang, Q.; Huang, Z. Laminar Burning Velocity and Markstein Length of Nitrogen Diluted Natural Gas/Hydrogen/Air Mixtures at Normal, Reduced and Elevated Pressures. Int. J. Hydrogen Energy 2009, 34, 3145-3155. [CrossRef]

25. Bradley, D.; Gaskell, P.H.; Gu, X.J. Burning Velocities, Markstein Lengths, and Flame Quenching for Spherical Methane-Air Flames: A Computational Study. Combust. Flame 1996, 104, 176-198. [CrossRef] 